\title{
Electrical Retail Tariff Model Based on the Load Characteristics
}

\author{
J.J. Wu, H.T. Huang, C. Gao, F. Yu \\ College of Electric Power Engineering \\ Shanghai University of Electric Power \\ Shanghai, China
}

\author{
J. Pan \\ Jinhua Electric Power Company, State Grid Zhejiang Electric \\ Power Company \\ Jinhua, Zhejiang Province, China
}

\begin{abstract}
According to the recent policy requirements in China, which present to built the users classification of electrical retail tariff base on the users load characteristics, this paper put forward the consumers classification according to the voltage grade and load factor, and design the pricing system considering of the load characteristics. Combining with the power system and electricity price system environment in China, this paper deeply analyses the system cost including the marginal capacity cost and marginal electricity cost; then apply the marginal cost pricing and cost-based pricing to build the load factor electrical retail tariff model. This model is more fair compared with the traditional model in capacity cost allocation; finally, its effectiveness is proved in the example.
\end{abstract}

Keywords-electrical retail tariff model; consumers classification; voltage grade and load factor

\section{INTRODUCTION}

The reasonable cost allocation guarantees the electrical retail tariff well operating, but current consumers classification system in China is primarily based on the trade, which is defective to reflect the different affect of power cost between different users. This price system have rebelled against the fair burden pricing principle. Therefore, National Development and Reform Commission of China put forward the retail tariff reform twice in 2003 and 2013. The reform clearly requires to simplify the price classification into three categories including resident living, agricultural production and trade and other users. The latter tranche is further classified according to the voltage grade and load factor, then form the classification system based on the users load characteristics.

In the early 50's of last century, pricing mechanism based on the load characteristics classification has already been applied in some developed countries such as France. In China, it is still in the theoretical research stage and achievement is rare. The main achievement so far include: literature[1-2] has formed mature marginal cost pricing model. That method classified users according to the voltage grade and load factor and established a load factor pricing model. However, that model uses simultaneity factor to calculate the marginal capacity cost of each class users, which has deviation in the capacity users occupied at the system peak time. In addition, it isn't accord with the power system and electric price system environment in China; literature[3-4] discuss the necessity, theory evidence, policy design and foreign experience of the load factor pricing, but didn't construct the load factor pricing models suitable for China.

Therefore, this paper proposes a user classification method based on the voltage grade and load factor, and designs a retail tariff system according to the load characteristics. Combining with the electric power system and electricity price system environment in China, this paper deeply analyses the system cost including the marginal capacity cost and marginal electricity cost in servicing users; then apply the marginal cost pricing and cost-based pricing to build the load factor retail tariff model. This model is more fair compared with the traditional model in capacity cost allocation; finally, its effectiveness is proved in the example.

\section{BASIC FRAMEWORK OF LOAD FACTOR PRICING}

In addition to some political tariffs such as the preferential price for the residents, electricity price shall reasonably reflect the real cost of power supply. However, nearly all consumers are different in the cost of power supplying, so that variant tariff should be set for each consumer in theory, but it is not practical. Therefore, consumers should be classified into several classes according to the load characteristics, and then tariff should be set for each class of users.

Combining with the advantages of marginal cost pricing and cost-based pricing, this paper classifies consumers considering the load characteristics and build a hybrid load factor pricing method. The procedure is described briefly below: 1) Carry out analysis of the users load characteristics, acquire users load factor, simultaneity factor, system simultaneity factor indexes and their statistical relationship; 2) Select the load factor and voltage grade as the users classification indexes, formulate the consumers classification system according to the load factor; 3) Account the system financial cost of the power supply; 4) Calculate users marginal capacity cost and marginal electricity cost of each class; 5) Allocate the total cost to each class users according to the marginal cost, and set tariff to each class. The basic framework is showed in Figure 1. 


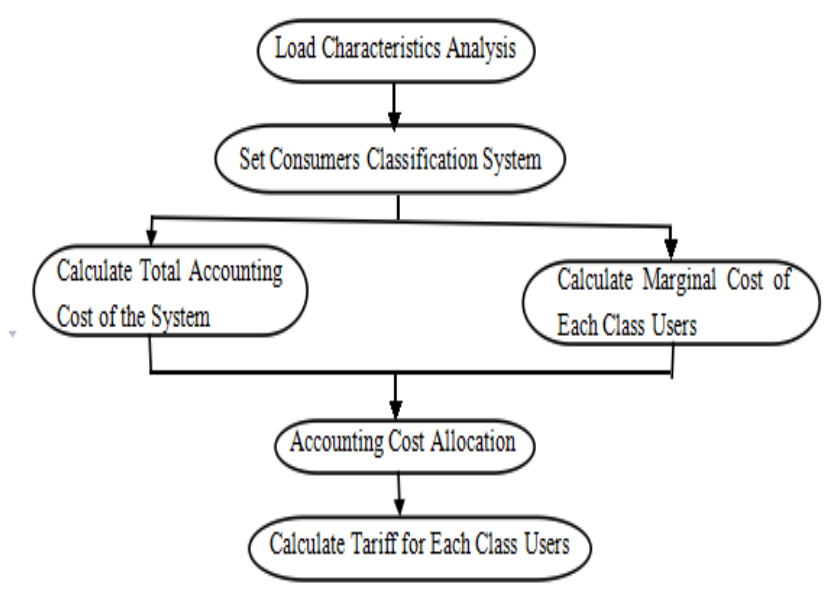

FIGURE I. BASE FRAMEWORK OF LOAD FACTOR PRICING.

\section{CONSUMERS ClASSify Model}

\section{A. Consumers Classification Index}

Allocation of the system cost refers to not only the cost of the power generation, transmission and distribution, but also the capacity and energy cost. In that case, multiple indexes should be utilized to reflect it synthetically. In case of the complexity of the consumers classification, load factor and voltage grade are chosen as the most typical indexes to classify users.

Consumers of the different voltage grade have difference in the cost of the power transmission and distribution, because of the distinctions of the facilities and lines users occupied. High voltage consumers occupy only the facilities of the high voltage, while low voltage consumers occupy the facilities of the low voltage in addition. Therefore low voltage consumers bear more power transmission and distribution cost. Load factor refers to the ratio of the average load within a certain period and the maximum load. It reflects the consumers utilization of the power supply facilities, consumers of high load factor utilize the power generation, transmission and distribution facilities more effectively, so improving the consumers load factor could reduce the fixed cost, and then achieve the system load curve smoothing, reducing the unit cost of power supply. In consequence, consumers of high load factor should bear less unit cost, and vice versa.

Because of the limited space, this paper only discusses the problems of consumers classification pricing according to load factor of the same voltage grade.

\section{B. Load Factor Classify Method}

Basic principle of setting load factor classification is to ensure that consumers within the same class share similar electricity price, while the weight of consumers in each class is not too small. According to the international experience, users will usually be classified into 3-6 files according to the load factor. The specific formulation method and procedure is showed in Figure 2: first collect all or sample users load factor indexes to statistic and analysis; second classify the consumers according to the load factor by 0.05 interval into 20 gears and calculate users amount and the theoretical price ratio; then merge certain consumers on the base of the principle, on that base confirm file number and level; finally, on the base of the elementary load factor classification, confirm the final classification considering to simplify the catalogue price.

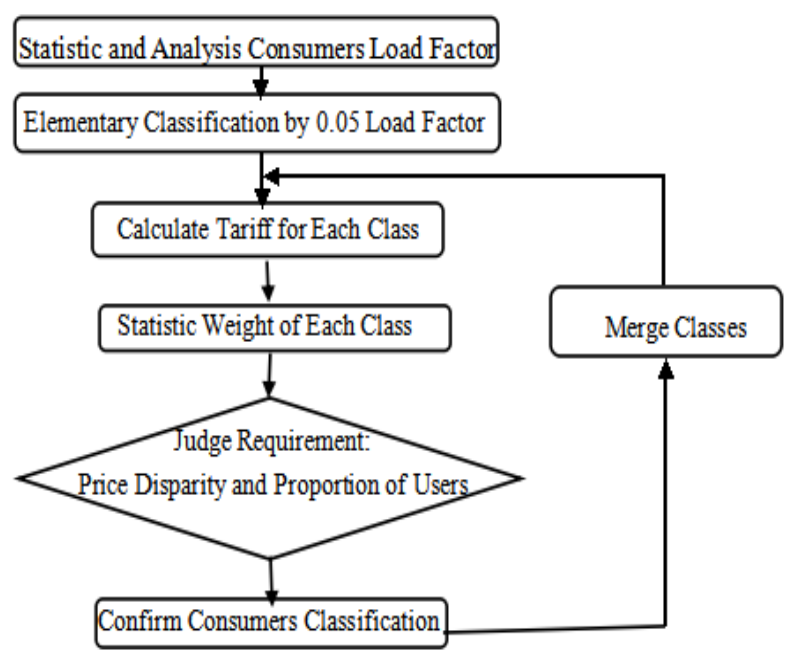

FIGURE II. CONSUMERS CLASSIFY PROCEDURE.

\section{Marginal Cost of Power Supply}

Power marginal cost can be divided into marginal electricity cost, marginal capacity cost and consumer cost. In this paper, the load factor pricing is only aimed for large consumers, consumer cost take a little of its cost, so it can be ignored.

\section{Marginal Energy Cost}

Marginal electricity cost is associated with the electricity consumption, it is the operating cost for providing additional $\mathrm{kWh}$. Under the traditional vertical integration system, it mainly consists of the fuel cost of the corresponding marginal plants at system operation time. Power generation companies and power companies in China are independent of each other, so the purchase price isn't Tou tariff and is single electricity price. In that case the purchase cost per kWh at any time is uniform, namely the average purchase tariff and the cost of loss. The later take a very small proportion, it is relevant with the users voltage grade.

\section{Marginal Capacity Cost}

Marginal capacity cost is increment capacity cost attribute to an incremental demand increase. It is relevant with the maximum demand of consumers. It shall generally include two parts, the marginal cost of generation and the marginal cost of transmission and distribution (MCT\&D). However in China the power purchase price is signal tariff, so the marginal cost of generation capacity is void. Therefore, the marginal capacity cost shall be MCT\&D.

MCT\&D consist of two parts, one is the MCT\&D of the exactly voltage grade (represented as "MCT\&DB"), the other is the MCT\&D of the higher voltage grade (represented as "MCT\&DG"). For the higher voltage grade, incremental capacity investment is needed to meet the incremental load at 
system peak time, on the contrary, incremental demand at offpeak time cost nothing. Therefore, according to the peak load responsibility law, at peak time, MCT\&DG can be calculated by the average transmission and distribution investment at a certain period. For the exactly voltage grade, users dispersion rate is high, there is deviation between the time when users load is maximum and the system peak time, at any time load increment will cause incremental transmission and transformer capacity cost. Therefore, MCT\&DB will emerge at any time, it can still be calculated according to the average transmission and distribution investment at a certain period.

\section{Method of LOAD FACTOR ClassificAtion TARIFF}

Capacity and energy cost is approximatively proportion to the consumers maximum power demand and consumption. Therefore, the consumers could pay the bill by means of basic tariff and electricity tariff and take different billing methods, which is called two-part electricity price.

\section{A. Basic Tariff}

In a certain period, MCT\&DG and MCT\&DB were calculated as MC1sr and MC0sr. If the class i consumers load factor is fi; system simultaneity factor is dsi, which represents the ratio of the comprehensive maximum load of the users at the system peak time and the sum of all the maximum load of every user; simultaneity factor is di, which represents the ratio of the comprehensive maximum load of the users and the sum of all the maximum load of each user. When sum of the maximum demand of all of the class i users increase $1 \mathrm{kWh}$, the system maximum capacity increased dsi kWh, so MCT\&DG increment is (dsi * MC1sr) according to the peak load responsibility law. For the reason that incremental demand at any time will occupy transmission and distribution facility of that voltage grade, so MCT\&DB should be calculated according to the users maximum comprehensive load, ie (di* MC0sr). As mentioned before, marginal capacity cost of class i is MCsr:

$$
M C_{s r, i}=d_{s i} \times M C_{s r}^{1}+d_{i} \times M C_{s r}^{0}
$$

The proportion of MCOsr in MCsr is k. Then the theoretical based price ratio of class $\mathrm{j}$ and class $\mathrm{i}$ users could be calculated as follow:

$$
b_{j, i}=\frac{d_{s j} \times(1-k)+d_{j} \times k}{d_{s i} \times(1-k)+d_{i} \times k}
$$

After financial accounting, the transmission and distribution capacity cost a certain voltage grade bear is expressed as Csr, system capacity is Pmax, the average system capacity cost is Csr/Pmax. Total capacity of cost of power system is allocated to all load factor classification users, then the basic price of class i users will be:

$$
q_{i}=\frac{C_{s r}}{\sum_{1}^{l}\left(b_{i, 1} \times P_{\max i}\right)} \times b_{i, 1}
$$

where qi=basic price of class i users; Pmax=maximum load of class i users; l=number of users classes; bi,1=let reference users be the first class of users, bi, 1 is the price ratio of class $i$ users and the reference users.

\section{B. Electricity Price}

Total annual power purchase price for power company is Csd, purchases of electricity is Qs, the average power purchase price is denoted as Csd/Qs, the average loss rate of that voltage grade is s. As mentioned, marginal electricity cost is the sum of average power purchase price and network loss cost:

$$
M C_{s d, i}=\frac{C_{s d}}{Q_{s}}+\frac{C_{s d}}{Q_{s}} \times \frac{s}{1-s}
$$

Because the marginal cost is calculated as the average cost, allocation of financial cost is similar to that of marginal cost.

\section{CASE STUdy}

\section{A. Example Description}

Example takes nearly 700 sample consumers from a certain province of 2013 in China, whose voltage grade is $35 \mathrm{kV}$ and capacity is beyond 315kVA. Dates collected include the load date, electricity consumption and the catalogue price of each class consumers. July18 is the maximum load day, so it's be chosen as the representative day. Example distills the date of that day to analysis users load characteristics. The average cost of $35 \mathrm{kV}$ is $0.6346 \rightrightarrows / \mathrm{kWh}, \mathrm{MCT} \& \mathrm{D}$ proportion is $20 \%$. MCT\&DB take $20 \%$ of MCT\&D. Example aims to classify the sample consumers by load characteristics, and calculate the tariff of each class.

\section{B. Load Characteristics}

Obtain the consumers load factor indexes according to users real load curve, then calculate the simultaneity factor and the system simultaneity factor and fitting the curve. Figure 3 displays the load factor-simultaneity factor curve and the load factor-system simultaneity factor curve of the sample consumers of $35 \mathrm{kV}$.

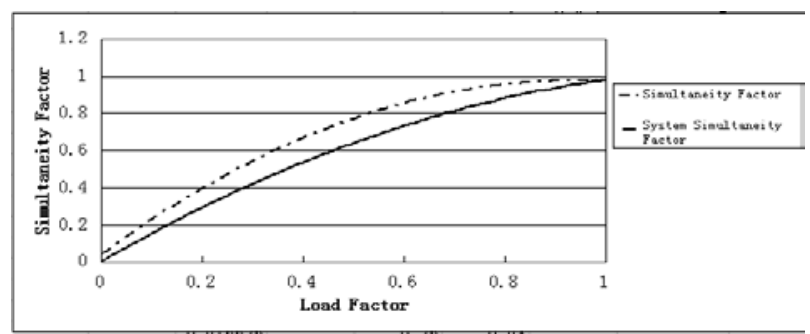

FIGURE III. LOAD FACTOR-SIMULTANEITY FACTOR CURVE \& LOAD FACTOR-SYSTEM SIMULTANEITY FACTOR CURVE. 


\section{Result of the Load Factor Classification Tariff}

For the capacity of the sample consumers is all beyond $315 \mathrm{kVA}$,and it's belong to China present two-part tariff implementation range, so all sample consumers could be set load factor classification and formulate two-part tariff for.

\section{1) Load factor classification}

Distribution of the sample users load factor is showed in Figure 4. According to the principle that customers within the same class share similar electricity price, while the weight of customers in different class is not too small, and file number should be appropriate, preliminarily classify the consumers by 0.05 interval of load factor, finally classify the consumers into 3 classes after merging and adjusting. The classification is showed in Table 1.

TABLE I. CONSUMERS CLASSIFICATION BASED ON THE LOAD FACTOR.

\begin{tabular}{|c|c|c|c|}
\hline $\begin{array}{l}\text { Load Factor } \\
\text { Classification }\end{array}$ & $\begin{array}{l}\text { Load } \\
\text { Factor }\end{array}$ & $\begin{array}{l}\text { Simultaneity } \\
\text { factor }\end{array}$ & $\begin{array}{c}\text { System } \\
\text { Simultaneity Factor }\end{array}$ \\
\hline $1^{\text {st }}$ Class: $\quad 0-0.45$ & 0.33 & 0.60 & 0.48 \\
\hline $2^{\text {nd }}$ Class: $0.45-0.75$ & 0.61 & 0.83 & 0.72 \\
\hline $3^{\text {rd }}$ Class: $\quad 0.75-1$ & 089 & 0.97 & 0.96 \\
\hline
\end{tabular}

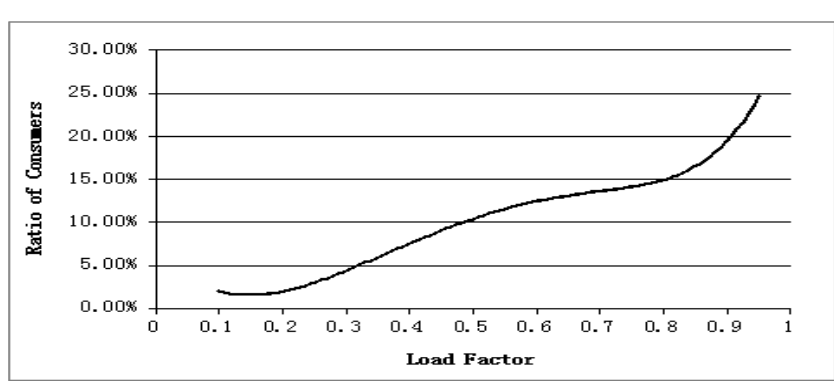

FIGURE IV. STATISTIC OF LOAD FACTOR DISTRIBUTION.

\section{2) Load factor classification tariff}

According to the classification in 5.3.1, obtain the consumers simultaneity factor and system simultaneity factor indexes, adopt the method mentioned in 5th quarter and the method from literature[1] to calculate the two-part tariff of each class. The result is showed in Table 2. The method mentioned in this paper is called "Method 1", the method taken from literature[1] is called "Method 2".

\section{TABLE II. TWO-PART TARIFF BASED ON THE LOAD FACTOR} CLASSIFICATION.

\begin{tabular}{|c|c|c|c|c|c|c|}
\hline & \multicolumn{3}{|c|}{ Method 1* } & \multicolumn{3}{|c|}{ Method 2* } \\
\hline & $\begin{array}{l}\text { Basic } \\
\text { Price } \\
\end{array}$ & $\begin{array}{c}\text { Electricity } \\
\text { Price } \\
\end{array}$ & $\begin{array}{c}\text { Average } \\
\text { Price } \\
\end{array}$ & $\begin{array}{l}\text { Basic } \\
\text { Price } \\
\end{array}$ & $\begin{array}{c}\text { Electricity } \\
\text { Price } \\
\end{array}$ & $\begin{array}{c}\text { Average } \\
\text { Price } \\
\end{array}$ \\
\hline $1^{\text {st }}$ Class & 40 & 0.5232 & 0.6406 & 48 & 0.6220 & 0.7142 \\
\hline $2^{\text {nd }}$ Class & 59 & 0.5232 & 0.6097 & 60 & 0.5971 & 0.6218 \\
\hline $3^{\text {rd }}$ Class & 76 & 0.5232 & 0.5964 & 76 & 0.5154 & 0.5872 \\
\hline
\end{tabular}

* Unit of basic price is $¥ / \mathrm{kW} /$ mouth, unit of electricity price and electricity price is $¥ / \mathrm{kWh}$

\section{Result Analysis}

Figure 5 shows the load curve of the 1st and 2nd class and the $35 \mathrm{kV}$ system. As showed in the Figure 5, 1st class consumers load factor is lower, the load fluctuate according to the time obviously, peak-valley is larger, so the operating factor of the facility is lower. This means that the average price of the low load factor users is higher for that they should allocate more capacity cost per unit. The calculate results of the two method showed in the Table 1 are correspond to the theoretical analysis. This means two method all could better reflect the fair burden principle.

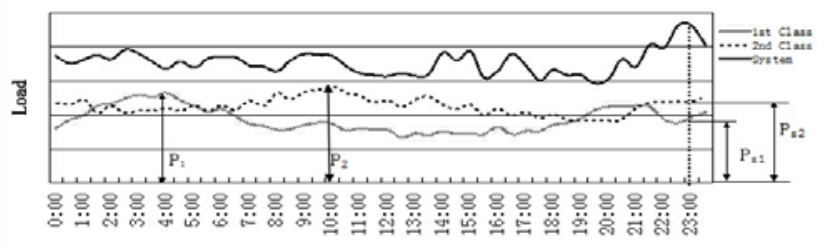

FIGURE V. DAILY LOAD CURVE OF LOAD FACTOR CLASSIFICATION CONSUMERS.

Besides, dates of the first two classes consumers are showed in Figure 5 and Table 3. Method 1 allocates the capacity cost according to the compositive load Ps1 and Ps2 at peak time of system, while method 2 use the compositive maximum load P1 and P2 of each class. Method 2 doesn't reflect peak load shifting reasonably, so the capacity cost consumers bear is more than method 1 . In conclusion, compared with method 2, method 1 utilizes the system simultaneity factor to reflect peak load shifting, which will better reflect the real capacity occupation at peak time of system. In that case, method 2 could allocate cost more scientifically.

TABLE III. COMPARISON OF TWO METHOD IN CAPACITY COST OF EACH CLASS USERS.

\begin{tabular}{|c|c|c|}
\hline $\begin{array}{l}\text { Load factor } \\
\text { Classification }\end{array}$ & $\begin{array}{c}\text { Method } 1 \\
\text { ( } ¥ / \text { kW/Mouth) }\end{array}$ & $\begin{array}{c}\text { Method } 2 \\
\text { ( } ¥ / \mathbf{k W} / \text { Mouth) }\end{array}$ \\
\hline $1^{\text {st }}$ Class: $\quad 0-0.45$ & 40 & 51 \\
\hline $2^{\text {nd }}$ Class: $0.45-0.75$ & 59 & 62 \\
\hline $3^{\text {rd }}$ Class: $\quad 0.75-1$ & 76 & 78 \\
\hline
\end{tabular}

\section{CONCLUSION}

According to the recent policy requirements in China, which presents to built the users classification of electrical retail price classification structure base on the users load characteristics, this paper design the retail price system based on the load characteristics, and build the load factor pricing model suit for China. On the one hand, the model is closely connected with the electric power system and price policy in China, on the other hand, compared with the simultaneity factor, this model utilizes the system simultaneity factor to reflect peak load shifting, which will better reflect the real capacity occupation at peak time of system. System simultaneity factor could reflect the occupation of capacity at peak time of system. and it will make capacity cost allocation more scientific. 


\section{ACKNOWLEDGEMENT}

This work is supported by National Natural Science Foundation of China 71203137.

\section{REFERENCES}

[1] L.S, Zhao. 1992. Electric Pricing Design--Marginal Cost Pricing Application. Beijing: Hydraulic and Electric Power Press.

[2] World Bank Staff Working Paper No.340. 1979. Electric Power Pricing Policy. Washington, DC.

[3] Z.Y, Tan. 2013. The Theory Basis, Calculation Method and Policy Options for Load Rate Tariff. Changsha: Hunan University.

[4] Z, Ye. \& S, Yao. 2014. Research of Load Factor Tariff Implement in China. Price Theory and Application5: 44-46 